\title{
O rigin of the Center for Geochronological Research at São Paulo
}

\author{
John Hamilton Reynolds (in memoriam) \\ Presented at ther First SSAGI, 1997, Campos do Jordão, SP, BRA
}

\begin{abstract}
Please excuse my making this account totally personal. In evoking the origins of the Center I pretty much lack outside documentation. Much of what you will hear is thus what I remember. Memories are, as you know, highly fallible. People my age can not only fail to remember what happened but worse still can succeed in remembering things that didn't happen! Happily I kept a journal of my association with this project. About once a week I would dictate my account of the previous week's activity and, from time to time send plastic "Dictabelts" back to Berkeley for transcribing. There resulted, finally, some 530 typewritten pages of documentation. I shared these with the US National Science Foundation as they were typed up and, of course, kept a copy for myself. I have referred conscientiously to this journal in writing my report. It suffers from many inadequacies but at least the material in it was written within a few days of its occurrence and the impressions, subjective as they may be, were at least fresh. So, _ let us begin.
\end{abstract}

I remained working at Berkeley for all of my professional life. There are dangers in that, but Berkeley has a very enlightened policy about sabbatical leaves - after every 6 years of service you can be away for a year on $2 / 3$ salary. And I took full advantage of that program. I liked to be partly a traveler on those leaves and partly engaged in something useful. When it came time to think about a plan for my second sabbatical leave in 1963-1964, an article by Patrick Hurley caught my eye. Partly the title read "How not to date a continent". As a non-geologist I did not pay much attention to his recipe, but I was struck by learning that for the most part there were no radiometric dates for South America. I had enjoyed teaching geologists at Berkeley how to measure dates. Why not go to South America and teach there for a year? The first step was to write a letter to several leading geology departments in South America and ask if they were interested in a joint project between the University of California at Berkeley, hereafter UCB, and their institution. The Brazilians at São Paulo came back immediately with enthusiasm. It just so happened that Frank Turner, a friend of mine at the Geology Department at Berkeley, was visiting the São Paulo department at the time and he encouraged them to respond quickly. By the time a friend of mine at Buenos Aires gave a similar response, it was too late. We had a deal with Brazil.

The deal involved obligations on both sides. UCB was to collect the equipment needed for a geochronology laboratory and arrange to bring it and me to São Paulo. The University of São Paulo, hereafter USP, was to provide suitable space for the lab and provide key personnel - one or more geologists and at least one physicist. USP was also responsible for getting funds for properly fitting out the space and for operating the lab. My own support would come from UCB but other personnel would be supported by USP.

My first task was to raise money for the equipment. I knew that in the short time I would be in Brazil we could only make important headway if I brought absolutely everything we needed from the US. So I had to sit down and make a list of everything needed - mass spectrometers, sample systems with an induction heater, glass equipment for filling sets of $38 \mathrm{Ar}$ spikes, a flame photometer for potassium analyses, ion exchange columns for $\mathrm{Sr}$ separations. Of course we had to locate the vendors for all that material and get their prices before a proposal could be sent to the U. S. National Science Foundation where we expected we could get support.

Things progressed and we got the money based on our lists of things needed. The big items were the mass spectrometers. At that time the Nuclide Corporation was fabricating glass instruments based on a Berkeley 
design so that we could order a complete mass spec of the kind we wanted for the argon analyses. I saw myself with a potential conflict of interest, so I specified that no royalties were to be paid to me as a result of the orders. It was important in my view to teach the Rb-Sr method in addition to the K-Ar method. An inexpensive way to do that was to design a modified glass tube in which a surface ionization source could be fitted for $\mathrm{Rb} / \mathrm{Sr}$ measurements. Such a mass spectrometer would not be a permanent solution for the $\mathrm{Rb} / \mathrm{Sr}$ capability, but would enable me to teach all the steps in determining $\mathrm{Rb}-\mathrm{Sr}$ ages. Later a proper mass spec could be added by the Brazilians. The glass tubes were fabricated for Nuclide by our Berkeley glass blower as an outside job so that I could conveniently oversee his work. We made spare glass tubes for both the argon and surface ionization instruments. There were two magnets and two pumping systems but shared electronics. Despite all our thinking ahead we had not reckoned on the substantial California Sales Tax for the equipment, some 6 percent. The solution to that problem, which was found by an energetic purchasing specialist at Berkeley - Mr. Howard Symonds - was to store all the material upon receipt in a sealed container for export. We couldn't test any of the equipment until we got to Brazil.

There are two amusing stories which come to my mind about this phase of the work. As part of USP's contribution to the project, the Geology Department there was asked to send a junior geologist to Berkeley to work with those geologists at Berkeley who were engaged in geochronology. This would give him or her a running start in learning the business. USP wisely sent Umberto Cordani, one of their best assistants at the time. From that time onward, Umberto was the chief Brazilian participant in the laboratory and became the de facto chief when I returned in 1964 to Berkeley. While at Berkeley, Umberto lived in my house and worked very hard and effectively in learning the ropes. He was so efficient that he had extra time to help me with assembling the equipment. I suddenly realized that we had neglected to put a cathode ray oscilloscope on the equipment list. The cheapest way to add such a piece of equipment was to buy a so-called Heathkit oscilloscope - an unassembled kit which the purchaser puts together himself. Umberto put it together in the apartment in my house where he was living. One morning he came down to breakfast looking completely undone and told us he had been incredibly foolish. Much of the wiring in the kit for the oscilloscope was in a preassembled harness. Umberto somehow though it was necessary to undo all that before attaching the wires. So he spent much time painfully taking apart a harness which eventually he had to put back together again. I can finish this story by saying it is the only mistake I ever remember Umberto making in all the work we did together.

I am the goat in the other story. We needed some $90 \mathrm{Sr}$ to use in calibrating our ion exchange columns. I obtained the isotope catalog from the government lab in Oak Ridge, Tennessee and noted that the minimum price for the isotope was that for a curie no matter how little you ordered. Being a thrifty New Englander by nature and having noticed that $90 \mathrm{Sr}$ had no gamma rays - only a beta minus activity which would be well shielded by ordinary packing - I said, "why not order a curie - other Brazilians might like to have a large supply of the isotope?" What I had overlooked was that although the short-lived daughter, 90Y, of the 29-year $90 \mathrm{Sr}$ also decayed predominantly by pure beta emission there was a $.02 \%$ branch to an excited state of 90Zr which emits a $1.75 \mathrm{MeV}$ gamma ray. In other words when the package arrived it was as hot as a pistol. A nearby Geiger counter would register large amounts of radiation and there were, for that reason, all sorts of restrictions about handling the package. Getting that "hot" package into safe hands in Brazil without causing a bureaucratic nightmare was a major source of worry for weeks to come.

We traveled to Brazil by freighter. There were two reasons. One was that I greatly enjoy sea travel. (Now that I am retired, for example, cruising in our sailboat has become a major activity with Ann and me). The other was that we had a lot of fragile equipment to transport safely to Brazil - glass mass spectrometer tubes, glass mercury diffusion pumps, the rudiments of a glass system for filling individual argon spikes and so on, not to mention much other delicate electronic instrumentation. The best way, thought I, to ensure safety of these cargo items was to accompany them on a ship and supervise all loading and unloading. A trick we always used in shipping the fragile glass items was to box them up in a wooden "coffin" with a transparent top. Even the roughest, toughest stevedore would exercise some care when he could look into the box he was handling and see a delicate piece of laboratory glass lying in state on its padding. So we had a leisurely time traveling by ship from Los Angeles to Santos Brazil, enjoying the passage through the Panama Canal and stopping at various ports in the Caribbean until we got to Santos.

We solved the problem of how to transport the radioactive package on the ship. The freighter had cargo winches which operated on the ship's DC electrical power. Just like a trolley car, or in Brazil I should say just like a "bonde" if that term is still used here, the speed of the winches is controlled by switching in and out resistances with high power ratings. On a ship these resistances are situated in a so-called resistor house, a metal closet, essentially, with 
stout steel walls where a crew member hardly ever goes a perfect place to transport a radioactive box. When we got to Santos and were ready to leave the ship, I retook possession of my radioactive box and put in one of my suitcases, hoping that they would not check incoming personal luggage with a Geiger counter. Fortunately they did not.

\section{Myself - then and now}

In starting to read the journal a few weeks ago I was confronted with recollections, attitudes, and feelings which date back 33 years. How on earth could I have been that intense? How could I have displayed that much energy? How could my co-workers have put up with me? I focused completely on having the project succeed. I evaluated everyone involved in terms of the extent to which they shared my goals and contributed to them. Except for Umberto, who always behaved in saintly fashion, I complain about all of these people at one time or another often unjustly so - in the pages of the journal. In short I am confronted with myself as a person I now don't particularly like. But on I somewhat admire for single-minded dedication to carrying out a plan. Much as one might admire a military officer who harasses his troops incessantly and expects far too much of them but in so doing drives them to great exploits and, with them, achieves the states objective. I am much more appreciative now of what others did on this project. Let me start by talking about some of these people.

\section{Umberto Cordani}

I start with the two Brazilians you are honoring today. Umberto was the happy choice of the faculty at USP to be the leading assistant for the geochronology laboratory and his time working with me and his subsequent distinguished career at São Paulo and on the international geologic scene have underscored that fact. As geologist, researcher, research director, professor, administrator, and international worker and spokesman for geology, his career has brought distinction to USP, Brazilian science, and the entire geological profession. The geological data base, "georef" we can call up on our PC's these days lists 120 publications under his name.

\section{Koji Kawashita}

When I got to São Paulo, the Brazilians had not yet obtained the services of a physicist assistant. They had, however, identified two young physicists who were possible candidates. They held provisional jobs at the Atomic Energy Institute at São Paulo near the Cidade Universitária with responsibilities for looking after a newly acquired Metropolitan Vickers mass spectrometer. The machine was a good one, it seemed, capable of both surface ionization and the usual stable isotope studies (carbon and oxygen). Their lab, however, lacked supplementary equipment and supplies, reliable electrical power, operating funds, and most of all any visible research program. Of the two men, Koji was by far more interested in what we were doing. His colleague was attracted by some promise of receiving a fellowship for training in Vienna as part of his affiliation with the Institute. Koji's chief, Professor Pieroni, did not seem to be averse to Koji coming to work for us. I had hoped we could get a trial arrangement so that both Koji and I could see how well we worked together but it turned out finally, and I'll never know unless Koji tells me whether the insistence was his or Professor Pieroni's, that we had to make a contract for Koji right off the bat. It turned out that the contract I was a little hesitant about was worth its weight in gold. Koji has been a mainstay of the laboratory ever since. It is his technical expertise, his interest in always improved instrumentation, his proclivity for hard work, and his dedication to the laboratory that have made it a lasting success. His 'georef' entries number 103.

\section{G ilberto Amaral}

He was the second geology assistant to be assigned to the project. Gilberto worked very hard as part of the crew who got the laboratory started. He was associated with those science projects that I worked on during my stay and was indeed a strong contributor to the K-Ar work. Because his name started with " $\mathrm{A}$ ", the first papers from the lab are authored by "Amaral et al". Gilberto had other interests in geochemistry so that he did not become, like Umberto and Koji, a permanent fixture in the lab but he was truly one of the pioneering contingent whose efforts played a big role in the success of the project. When I consult "georef" under his name I find 36 papers listed. Many of these are in the field of remote geological sensing so I infer he has changed to that field. 


\section{Viktor Leinz}

Professor Leinz was the senior professor of geology and the one to whom Umberto was attached as an assistant. The first paper we published in Geochimica Cosmochimica Acta contains a profuse and flowing tribute to Professor Leinz for his administrative support of the laboratory. I am told that several years after I left Brazil to return to Berkeley he finally came to understand what we were trying to do and to live up to the tributes we paid him in the literature. But while I was in São Paulo and for a few years thereafter he really did not have an understanding of our objectives and viewed the project more as some sort of prize to be captured in what could best be described as a power play. My Brazilian colleagues are of a mind that I should let bygones be bygones and not elaborate on these difficulties, but I think in writing a history there is a certain obligation not to cover up important but unpleasant facts. Dealing with Professor Leinz was somewhat like dealing with the weather - sometimes fair and warm and sometimes stormy. On the whole, however, these interactions were troublesome and consumed energy from all of us who were working hard to establish the lab. I am pleased that toward the end of his life he began to appreciate the principles we had established for the laboratory and the contributions of its staff to the reputation of the Geology Department, of which he had been the major founder, and indeed the reputation of the University as a whole. He now seems to be fondly remembered by those who served under him years ago.

\section{Norman Herz}

Norman was an American who preceded my coming to the Geology Department at USP as part of the AID program (Assistance for International Development) of the US Department of State. Outside assistance to geology at USP and elsewhere in Brazil actually began even earlier under a Brazilian program called CAGE (standing for "Campanha para Formação de Geólogos" or "campaign for the preparation of geologists") instituted by President Juscelino Kubitschek. The American contingent, under the AID program, were geologists seconded to that program by the US Geological Survey and included Professors John Stark, Gene Tolbert, and Norman Herz. Norman, who overlapped my year in Brazil for most of it after the other AID professors had left, gave a great deal of his time and effort to help our geochronology lab. It was he who helped solve the myriad personal problems I faced in getting established in São Paulo, finding a house to rent and a cook to help my wife, providing a vehicle to get around in before I bought a car - things of that sort. He was also an invaluable liaison with the American Consular office in São Paulo who had to participate in the free importation of our lab equipment through Brazilian customs and handle the documents for that process. That connection continued to be an absolutely indispensable one because we were able to import small spare parts and other needed items from Berkeley via the diplomatic pouch. To everyone's amazement, that useful pipeline postdated my time in Brazil for many years. Every now and then a badly needed item could get quickly from Berkeley to São Paulo in that way - the last instance being a scant few years ago. When the lab began to make measurements, Norman was one of the people, along with Brazilian geologists, that we brought into the programs discussions where his geologic expertise and familiarity with Brazilian geology were a valuable resource. Norman returned to the USGS for a few years but eventually returned to academia by joining the faculty at the University of Georgia. It is interesting that the work he is now famous for, marrying marble quarries and archeological artifacts by their carbon and oxygen isotopic signatures, involves the use of mass spectrometry. Herz is now a famous name in archeological geology.

\section{G eraldo Melcher}

Of all the Brazilian professors at USP, the one who most assisted the geochronology lab was he. Melcher was an expert field geologist who specialized in economic geology. He was also one of the most gifted linguists I have ever known. He was not only fluent in many languages but was truly multilingual, soon speaking languages which were new to him with very little trace of foreign accent. He told me in 1979 that despite no previous acquaintance with the Russian language he succeeded, after a then recent but brief stay in Russia, in understanding almost everything his Russian friends were saying. Moreover, advice from Melcher in dealing with the problems already mentioned in relation to Prof. Leinz was invaluable. My communication with other senior Brazilians at USP was hampered by my limited facility with the Portuguese language, adequate for most purposes in living there but not up to handling delicate interpersonal relationships. Not so with Melcher. And like Herz, he was extremely helpful in the discussions of our scientific program and quite willing to devote time in the field to that program. 


\section{Rui Franco}

In 1963, the Geology Department at USP was located in what had been a grand private house near the Governor's Palace on Alameda Glete. The ground floor was taken up by the Mineralogical Museum, presided over by Prof. Rui Franco. Franco was much admired as an expert on gems; much traffic in gem appraisal came his way. According to Frank Turner he was very discrete in this work. His notes might conclude, after a careful description of a large and rare gem, "this stone is remarkably similar in both description and weight to the famous Such-and-such stone which was stolen from So-and-so several decades ago." But the client could be sure that the comment went no further. Rui Franco was of great help to the lab as a professor of high standing in Brazil who wanted us to succeed, who was close at hand to our work, but had no designs on our undertaking. His standing in Brazil can be evaluated from the fact that he retired from his professorship at USP to become the chief of the educational division of Brazilian Atomic Energy Institute. His friendship and support were always much appreciated by the lab. I also owed him a large personal debt of thanks because he was able to arrange it so that my three young children attended an excellent state school in São Paulo when a new semester began in February. His arranging had nothing to do with his political influence. It came about because his sister had for many years been a classroom teacher at the school and thought that having my American children in attendance in three of their classes would be an unusual opportunity for the other children to interact with these North American neighbors. My children flourished at that school and came away from Brazil completely fluent in Portuguese. Unfortunately there was no way for them to maintain that skill back in Berkeley.

\section{Claudio Comerlatti}

He represents the hard working technicians skillful and dedicated, that assisted our operation - he was responsible for much of our wet chemistry and flame photometry. Another man who comes to my mind was our mechanic Donato, a technician belonging to the neighboring Chemistry Department.

\section{USP professors in other disciplines}

I would mention a few professors in other departments who helped the laboratory a great deal. Professor Oscar Sala of the Physics Department ran an ambitious and successful nuclear physics program, using a homemade Van der Graaf accelerator. He helped us obtain some needed shop work when revisions to our $\mathrm{Rb} / \mathrm{Sr}$ mass spectrometer proved necessary. His colleague in physics, Professor Quadros, met our needs in obtaining liquid nitrogen. We needed relatively small quantities so that commercial supplies, although obtainable, would have been impractical. Several professors in the biological sciences were helpful. Professor Crodowaldo Pavan, a well-known geneticist, ran an admirable program at USP. Some of his work was on Brazilian flies. He also did interesting work, using genetic observations on a small barren island under his complete control as a natural genetics laboratory. His aid to us was in the form of some voltage stabilizers badly needed by us which he could spare. Also in genetics was Professor Warwick Kerr, an expert on bees. Kerr was actually at another university but served while I was there as FAPESP, the State Agency Scientific Director of from which we obtained supplementary funding. That position rotated among prestigious professors who took on the job for limited terms. Kerr understood our problems with Professor Leinz very well and was able to help a good deal. Kerr's lab had the misfortune later of being the one from which African "killer" bees escaped into the American continents, showing that genetics can sometimes be a dangerous occupation even before cloning became possible. Finally, the marine biologist at USP, Professor Sawaya, provided help of an especially important kind. He gave may family the privilege of going from time to time, for a rest. Restoration at the station of Marine Biology of the USP at São Sebastião was an important thing for me and I always remember it. Professor Sawaya was an enthusiastic supporter of the Brazilian equivalent of the American AAAS - the American Association for the Advancement of Science (and publisher of Science magazine). At his urging I gave a paper at one of their annual meetings and came away with a good opinion of that organization.

\section{Technical difficulties}

Research projects always have these and they are not very interesting long after the fact. Those that were the most thorny I can recognize by the frequency of their men- 
tion in the index I prepared for the dictated journal. Notable in that way are the broken quartz still, the ammonia shortage, the fuse problem, and the problems filling the first set of argon spikes in Brazil.

Part of the quartz still was damaged at sometime during its shipment and needed replacement. Its lack held up all the wet chemistry tasks in our lab, because we needed ultra-pure distilled water for potassium, rubidium, and strontium chemistry. Completing the first radiometric age determinations in our lab so that we could publicize our coming on stream was a prized goal; despite having made great progress in determinations of radiogenic argon, we could not complete any age determinations until the more mundane potassium measurements were completed. So crucial did this problem become that I finally had to make a special trip to Rio to bring back as airline baggage the quartz part which had reached Rio safely but would not be accepted as freight by the airlines unless it were, carted, something I considered too risky - after something is crated there is nothing to ensure that it won't be tossed around and possibly damaged in transit.

The ammonia shortage had to do with a peculiar mindset then prevalent in Brazil. When ammonia was imported, there was plenty-despite the trouble and expense to the chemical companies in having it imported. When Petrobrás, the state oil company, started producing ammonia in a small way, the chemical companies stopped importing it despite the fact hat the local production was far less than demand. They simply told people who formerly got ammonia from them that there wasn't any - which in a way was true. I do not know how the Brazilian economy finally dealt with this problem. We needed so little in our operation that a friendly bureaucrat at Petrobrás whom myself and Umberto visited simply diverted one of their cylinders of liquid ammonia for our (more or less lifetime) use.

The fuse problem just about drove us crazy. We had adequate power from our own generator even during the rather frequent power interruptions. The problem was the two sets of fuses between us and the generator. Poor electric contacts in fuse holders can substantially lower the current rating because of the extra heat produced in the poor contact between wire and fuse. The solution was to install circuit breakers but it took weeks or even months before we could get delivery on the breakers. The generator we brought was to be housed in a brick shed. By the way, the Brazilian way to handle that was to install the generator and then build the brick shed around it. If the generator needed work it was considered an easy job to demolish the brick shed, repair the generator and start over. An elegant solution which probably would not occur in the US, where a large and costly shed with doorways would have been required.

The filling of large butches of argon 38 spikes was a series of successive troubles. The spike tubes were preweighed both empty and filled with mercury in order to know their volume. To finally fill the spikes, mercury was distilled into the system, a charge of spike argon was released in the volume and the mercury then gradually shifted by gravity from the reservoir into the capillaries so as to seal off the tubes before removing them with a torch. The volume of the system remained constant during the mercury transfer so that all tubes were filled at the same argon pressure. People wouldn't dream of such a procedure nowadays, but it had a great advantage when we were opening our lab to visiting workers. If they bungled, they could lose one spike but they could not destroy a carefully calibrated gas pipette. We brought one set of some 400 spikes to São Paulo from Berkeley but further spikes had to be filled in Brazil. My journal index contains about six long entries concerning the spike filling problem, all near the time I was trying to wind up affairs and leave Brazil. The shortest way to describe the situation is to remind you of Murphy's Law - if anything can go wrong it will. There was really only one expert glassblower we knew about. During the last part of my stay I believe he was halftime at the Nuclear Institute and halftime in a commercial shop of his own. To get the spike tubes assembled halftime in a commercial shop of his own. To get the spike tubes assembled for filling, we had to transport things back and forth between our lab and his shop. He had no annealing oven. We solved that problem by building our own. Its thermostat was unreliable and melted one subset of assembled spike tubes. I dropped another. And so on. When I left Brazil we had successfully filled about 185 tubes. The remainder, counting the ones I had not broken or melted, were totally filled with mercury for a second time when the system cracked on the operating table, so to speak. Koji had to deal with that problem after I left the country.

\section{0 ur scientific program}

The first two projects we undertook, and I am speaking now of our São Paulo group because visitors to the lab brought their own scientific projects, were a survey of the ages of various occurrences of the vast Paraná flood basalts and related diabases and a survey of the ages of various occurrences of alkaline rocks in Southern Brazil. These rocks were thought to be relatively young and appropriate for $\mathrm{K}-\mathrm{Ar}$ dating and were of considerable geologic impor- 
tance. These two projects were completed and eventually published in the journal Geochimica Cosmochimica Acta. Because my expertise was in the instrumental method and not in the geology, I was especially interested in the precision of the work. We carried out quite a number of replicate analyses so as to evaluate the analytical precision. The other question we were interested in was to what extent differences in age among the samples was real. To attack that question we selected diabase samples from fresh intrusive dikes where we could be confident that all samples from the dike should be contemporaneous within a very short time span. The results of these systematic studies were somewhat inconclusive. We found, for example, that in studying a particularly appropriate dike, sampled on the beach at a place called Ubatuba, that five of six samples taken from spaced intervals in the width of the dike were exactly the same in age, but the remaining sample was lower in age by about 10 percent. And we could find no property of the aberrant sample which could in any way explain the difference. Our general conclusion was that the true accuracy of the method was good enough, except for rare instances, so that the observed spread in the ages of the Paraná basalts was real. Much more recent work, by Renne and others, shows that we were wrong and that by newer techniques the ages of the basalt floods prove to have a much smaller spread. I can brag a little here and comment that just at the time we were perplexed about this problem in São Paulo, work was going on in my lab back in Berkeley that developed the needed experimental technique. I refer to the discovery of the argon 39-40 method by Merrihue during his thesis work with me and published in 1965. The new measurements by Renne et al use the 3940 method and incremental heating so that instances of argon loss or argon inheritance can be detected and discarded from the uncomplicated plateau ages.

Another project worthy of mention concerns the dating of older rocks in the northeast of Brazil, near the bulge in the coastline which has always been strongly suggestive of a former fit with a corresponding indentation in the west coast of Africa. The boundaries between geological provinces in that region run in such directions there should be similar patterns between old South American and old African rocks if the regions were once connected and continental drift has subsequently occurred. This was a project where Rb-Sr dating would also be important. According to my journal, the idea of dating these Brazilian rocks was mentioned in the original NSF proposal - something I later had to document as you will see. On May 25, 1964, we received a letter form Patrick Hurley of MIT describing a large collaboration being organized to carry out this "crucial experiment to test the hypothesis of continental drift".
According to Hurley's letter, Steve Moorbath's lab at Oxford was to have pretty much a monopoly on dating the African rocks, but there was to be much US involvement in the work on the Brazilian rocks. When Hurley's letter came, we got together people at USP and decided that we would participate actively and strongly in the project and made concrete plans for the necessary field work in the northeast region and for its funding. Melcher was to play a major role in the field work, along with Gilberto and others. Our response to Hurley generated a second letter from Hurley that we found disturbing because it painted a picture of our lab as a fledgling enterprise that "needed to be brought along to maturity and sophistication by helpful contact with other members of the collaboration", and not in any way be the major player in the South American work. This letter went over with us like the proverbial lead balloon and had me documenting for Hurley our earlier proposal to NSF and our intention to engage strongly in the project irrespective of what others did, although we welcomed their participation with us if they so chose. The next and final letter from Hurley during my stay at USP said it had all been a misunderstanding and they did not want to horn in on our area now that they understood the picture etc. all was sweetness and light again. The project went ahead at least at São Paulo and at MIT and resulted in a somewhat famous 1967 joint paper in Science which strongly supported the hypothesis of continental drift. The authors from USP, where field work and K-Ar ages were done, were Fernando de Almeida, Geraldo Melcher, Umberto Cordani, Koji Kawashita, and Paul Vandoros. The authors from MIT, where $\mathrm{Rb} / \mathrm{Sr}$ work was done on Brazilian samples, were Hurley, J. R. Rand, W. H. Pinson Jr. and H. W. Fairbairn. The African data were taken from the literature. Hurley later wrote a Scientific American article about the work. The MIT - São Paulo paper in 1967 came at a time when there was an explosive output of evidence for continental drift, sea floor spreading and plate tectonics. As you can see, our lab had a role in this scientific revolution.

\section{The visitor program}

From the very first we planned for the laboratory to be open to geologists who cared to visit and to be instructed by us in running their own samples. By this means the scope of the work would be expanded and geochronology in South America would be advanced more than would be the case with a closed lab in São Paulo. We also expected that by directly involving people from other institutions in 
radiometric dating there would eventually be spin off of other laboratories for radiometric dating in South America Our approach was to disseminate this invitation by letters to other institutions on the continent. Our hopes in this regard have been fully realized. Even in the first year of operation we enjoyed considerable participation by visitors.

Jonathan Bushee, a geology graduate student of Frank Turner's was our first visitor. Having a Berkeley graduate student was planned from the first so as to strengthen the collaborative relationship between UCB and USP. Jonathan's thesis topic, under Turner's direction, was a study of alkaline rocks. In particular, since a survey of the ages of alkaline rock localities had been preempted as one of "in-house" projects, Bushee's special project was to be a detailed study of the Poços de Caldas alkaline complex, although he participated with the group in the survey as well.

Two scientists form Argentina were the first visitors to respond to our letter of invitation, namely Horacio Cazeneuve, a physicist, and geologist Angel V. Borrello both of the University of La Plata. From my journal I find that they visited us in mid-December of 1963 and mainly explored the possibility of setting up their own lab in Argentina. I urged them to send people here for hands on training while I was here, but nothing happened until I left Brazil. According to "georef" Cazeneuve published a paper in 1965 containing dates form samples form Argentina so that he must have worked in the lab briefly. The first visitor to really grab the opportunity with both hands and make something of it was Fernando Munizaga from Chile. He appeared in São Paulo on April 4, 1964 with samples in hand (and more on the way) prepared to spend three months with us. Within five days he was running an argon extraction line with one of his samples loaded. His three months stay was very productive and near the end he was asked by his colleagues in Chile to stay longer. I do not remember what happened in that respect but it was clear at the time that he needed a rest. I was able to arrange with Prof. Sawaya that he visit the marine biology station for some restoration, just as I had needed on several occasions.

Our first visitors from other places in Brazil were Homero Lenz Cezar and Jorge Gerken from Fortaleza and Belo Horizonte respectively. These visitors were unusual in that they had had experience with radiometric dating and mass spectrometry earlier on. Homero had been a student at Oxford working in Ken Maune's laboratory. I had not met him but my Berkeley postdoc at the time, Grenville Turner had overlapped with him at Oxford. Jorge had spent some time with Tom Aldrich's group at the Carnegie Dept. of Terrestrial Magnetism in Washington DC, as well as a year in Minneapolis. I was especially interested in getting them involved because of their experience and I was able to find some left over NSF funds to pay most of their expenses. They were here for most of July and accomplished quite a bit. They were very helpful to me in helping to get the kinks out of our $\mathrm{Rb} / \mathrm{Sr}$ work. Between them they ran quite a few of their samples for K-Ar dates. These were samples form the State of Ceará. Sometime later Homero and a geologist, Gerhard O. Schrader, must have returned from Fortaleza and measured some definitive $\mathrm{Rb} / \mathrm{Sr}$ dates on the Ceará samples because I have a treasured reprint of a paper (in English) by Koji, Homero and Schrader which is the only description in English of which I am aware about the small glass surface ionization machine and the successful work it did. Most of these people were at my house on the evening of July 24 for an evening of heavy eating and music making.

\section{Fond memories}

I have about used up my time, so I will simply conclude this very personal account by saying how fondly I look back on the project as one of the high points in my life. The year was a mixture of hard work, new experiences for myself and family, interesting travels, and interactions with many people who came to be lifelong friends. Lasting satisfaction from having done this work has come from seeing that the precepts we had in mind for the laboratory have been maintained over all these years, something to which this meeting will certainly attest. 